\title{
Hypovolaemia was associated with clustering of major cardiovascular risk factors in general population
}

\author{
Xianglei Kong ${ }^{1 \dagger}$, Xiaojing $\mathrm{Ma}^{2 \dagger}$, Jing Yao ${ }^{3}$, Shuting Zheng ${ }^{4}$, Meiyu Cui ${ }^{1}$ and Dongmei $\mathrm{Xu}^{{ }^{*}}$
}

\begin{abstract}
Background: Previous studies indicated that the clustering of major cardiovascular disease (CVD) risk factors is common, and multiple unhealthy lifestyles are responsible for the clustering of CVD risk factors. However, little is known about the direct association between the volume load and the clustering of CVD risk factors in general population.
\end{abstract}

Methods: We investigated the association of the clustering of CVD risk factors (defined as two or more of the following factors: hypertension, diabetes, dyslipidemia and overweight) with volume load, which was evaluated by bioelectrical impedance analysis. Hypovolaemia was defined as extracellular water/total body water (ECW/TBW) at and under the 10th percentile for the normal population.

Results: Among the 7900 adults, only 29.3\% were free of any pre-defined CVD risk factors and $40.8 \%$ had clustering of $\mathrm{CVD}$ risk factors. Hypovolaemia in clustering group was statistically higher than that either in the single or in the none risk factor group, which was $23.7 \%$ vs. $17.0 \%$ and $10.0 \%$, respectively $(P<0.001)$. As a categorical outcome, the percentage of the lowest quartiles of ECW/TBW and TBW/TBWwatson in clustering group were statistically higher than either those in the single or in the none risk factor group, which were $44.9 \%$ vs. $36.9 \%$ and $25.1 \%(P<0.001)$, $36.2 \%$ vs. $32.2 \%$ and $25.0 \%$, respectively $(P<0.001)$. After adjusting of potential confounders, hypovolaemia was significantly associated with clustering of CVD risk factors, with an OR of 1.66 (95\% Cl, 1.45-1.90).

Conclusions: Hypovolaemia was associated with clustering of major CVD risk factors, which further confirms the importance of lifestyle for the development of CVD.

Keywords: Volume load, Cardiovascular disease, Bioelectrical impedance analysis, Body fluid composition

\section{Background}

Cardiovascular disease (CVD) is the main cause of mortality and morbidity worldwide [1-3]. Hypertension, diabetes, dyslipidemia and overweight are the major risk factors of CVD [4-6]. In China, the prevalence of clustering of major CVD risk factors was $36.2 \%$, only $31.1 \%$ were free of any pre-defined CVD risk factors [7].

Multiple unhealthy lifestyles, including habitual drinking, physical inactivity and use of NSAIDs, are responsible for clustering of CVD risk factors [7]. In addition, lifestyle interventions e.g., physical exercise and consuming a low-

\footnotetext{
* Correspondence: qianyixdmgmail@163.com

${ }^{\dagger}$ Equal contributors

'Department of Nephrology, Qianfoshan Hospital, Shandong University, No.16766, Jingshi Road, Jinan 250014, PR China

Full list of author information is available at the end of the article
}

fat diet, may effectively prevent the development of type 2 diabetes, hypertension and dyslipidemia in high-risk subjects [8-10]. Therefore, comprehensive lifestyle interventions may be an effective strategy to control CVD risk factors and reduce the burden of CVD. Methods for screening the risk of CVD is a fundamental strategy for the primary prevention of CVD, but the patients with the highest risks should be identified in order to maximize the benefit/cost ratio of treatments.

Clustering of CVD risk factors was positively associated with Chronic kidney disease (CKD) [11]. Recent observations indicated that higher levels of water intake were associated with slower progression of CKD $[12,13]$. Epidemiologic evidence suggests that the balance of water intake and output may have implications for development 
of CKD. Hypovolaemia caused by arduous physical labor or high ambient temperaturemay be associated with CKD $[14,15]$. Arginine vasopressin (AVP), a crucial peptide hormone that regulates water homeostasis, may contribute to CVD progression In a rat model of 5/6 nephrectomy, increased water intake decreases AVP and reduces histological damage $[16,17]$. However, little is known about the direct association between volume load and clustering of CVD risk factors in general population. Therefore, we performed a cross-sectional study on a large scale population to examine the relationship between volume load and clustering of CVD risk factors, which was evaluated based on bioelectrical impedance analysis.

\section{Methods}

\section{Study population}

A total of 7900 adults who visited the Health Checkup Clinic consecutively in Qianfoshan Hospital of Shandong University were enrolled in the study. This study excludes outpatient or clinical patients. Patients with acute kidney injury, amputation, heart failure, severe liver disease, infection disease, malignant disease and pregnancy were excluded. Patients on diuretic drugs or any kind of renal replacement therapy were also excluded. The investigation was started in July 2010 and ended in December 2013. The ethics committee of Qianfoshan Hospital approved the study. All participants were given written informed consent prior to data collection.

\section{Blood biochemistry measurements and biometric parameters}

Blood was collected by means of venipuncture after an overnight fast of at least 10 hours. Serum creatinine was measured by the Roche enzymatic method using an automatic biochemistry analyzer (Roche P Modular with Roche Creatininase Plus assy, Hoffman-La Roche, Ltd., www.roche.com). Glomerular filtration rate (eGFR) was estimated using the Chronic Kidney Disease Epidemiology Collaboration (CKD-EPI) equation [18,19]. Decreased renal function was defined as the eGFR below $60 \mathrm{ml} / \mathrm{min} / 1.73 \mathrm{~m}^{2}$. Hemoglobin, fasting blood glucose, serum uric acid, serum total cholesterol (TC), lowdensity lipoprotein cholesterol (LDL-C), and triglycerides (TG) were also measured by automatic biochemistry analyzer.

Sociodemographic characteristics, health history (eg, hypertension, diabetes), and lifestyle behaviors were obtained through questionnaire. The body mass index (BMI) was calculated as weight (in kilograms) divided by height squared (in square meters). Blood pressure was measured using a sphygmomanometer, and three measurements were taken at 5 min intervals. The mean of the three readings was calculated, unless the difference between the readings was greater than $10 \mathrm{mmHg}$, in which case the mean of the two closest measurements was used. All of the investigators have completed a training program of the methods and procedures of the study.

\section{Body fluid composition}

Below are our methods to assess the components of body fluid composition. A multi-frequency bioelectrical impedance analysis (BIA) device (Body Composition Monitor, BMC, Fresenius Medical Care D GmbH), which measures 50 different frequencies 5 to $1000 \mathrm{kHz}$ was used. Input variables include the patient's height, weight, age, and sex. The measurements were performed after a 20-min resting period with the patient in the supine position. The procedure was performed for patients who had not consumed a heavy meal in at least 4 to 5 hours, or exercised 12 hours before the test, or consumed alcohol or caffeine 24 hours before the test. Electrodes were attached to the hand and foot on the nondominant side of the body, after the patient had been in recumbent position for $5 \mathrm{~min}$. The following parameters were collected: extracellure water (ECW), intracellular water (ICW), total body water (TBW), ECW/TBW. ECW was standardized by height (NECW). Anthropometric formulas with tracer dilution techniques (e g., Waston) have been widely used to calculate TBWwatson [20]. TBWwatson in normal healthy subjects (Watson's formula): Male, $2.447+$ $(0.09156 \times$ age $)+(0.1074 \times$ height $)+(0.3362 \times$ weight $) ;$ Female: $-2.097+(0.1069 \times$ height $)+(0.3362 \times$ weight $)$; Dry mass index $(\mathrm{DMI})=\left[(\right.$ weight-TBW $) /$ height $\left.\left.^{2}\right)\right]$; Lean body mass (LBM), which can be calculated using the formula (TBW/0.733) in BIA, are commonly used for accessing nutritional status [21].

\section{Determination of arterial stiffness}

cfPWV was assessed using the SphygmoCor device (AtCor Medical LtD., Sydney, Australia) as previously described [22]. A measuring tape was used to assess the distance between the carotid and femoral artery recording sites. cfPWV was calculated automatically by dividing this distance by the time interval between the rapid upstroke in the pulse wave at the carotid and femoral arteries using the peak of the R-wave on electrocardiography as a reference point.

\section{Assessment criteria}

We investigated the clustering of four major CVD risk factors, defined as two or more of the following: hypertension, diabetes, dyslipidemia and overweight. Hypertension was defined by the finding on three consecutive measurements at the clinic obtained two weeks apart of a mean systolic blood pressure of more than $140 \mathrm{~mm}$ $\mathrm{Hg}$ or a mean diastolic blood pressure of more than $90 \mathrm{~mm} \mathrm{Hg}$, or both, or patients already being priscribed by antihypertensive medicaments. Diabetes was defined 
as fasting blood glucose $\geq 7.0 \mathrm{mmol} / \mathrm{L}$ or the use of hypoglycemic agents or self-reported history of diabetes. Dyslipidemia was defined by the presence of at least one of the following: serum TC level $\geq 5.2 \mathrm{mmol} /$ $\mathrm{L}$, TG level $\geq 1.7 \mathrm{mmol} / \mathrm{L}$, or LDL-C level $\geq 3.4 \mathrm{mmol} / \mathrm{L}$ [23]. Overweight was defined as a BMI $\geq 24 \mathrm{~kg} / \mathrm{m}^{2}$ [24]. Hypovolaemia was defined as extracellular water/total body water $(\mathrm{ECW} / \mathrm{TBW})$ at and under the 10th percentile for the normal population $(\mathrm{ECW} / \mathrm{TBW} \leq 0.3167)$. As a categorical outcome, we calculated both the lowest and highest quartiles of ECW/TBW (0.3229 and 0.3357) and TBW/TBWwatson (0.8421 and 0.9008) for the normal population to describe the distribution of ECW/TBW and $\mathrm{TBW} / \mathrm{TBW}$ watson in different $\mathrm{CVD}$ risk factor groups.

\section{Statistical analysis}

Data were presented as proportions for categorical variables and mean \pm SD for continuous variables. The significance of differences in continuous variables between groups were tested using $t$ - test or one-way analysis of variables. The difference in the distribution of categorical variables was determined by Chi-square test. The association between hypovolaemia and clustering of CVD risk factors was analyzed using logistic regression models. Age- and Sex-adjusted adds ratios (ORs) with 95\% confidence interval (CI) were reported. We then used forward selection method and built a parsimonious model to adjust for other confounders. Covariates under consideration include age (continuous), sex (female vs. male), hypovolaemia, hemoglobin (continuous), eGFR (decreased or not ) and serum uric acid (continuous). We forced age and gender into the model.

All analyses were performed by SPSS statistical package, version 16.0 (SPSS, Inc., Chicago, IL). A $P$ value of less than 0.05 is considered statistically significant.

\section{Results}

The baseline clinical characteristics of participants were presented in Table 1. A total of 7900 individuals (5467males, mean age $38.8 \pm 8.5$ and 2433 females, mean age $37.4 \pm 7.3$ ) were enrolled in the study following the inclusion criteria. More than one half (52.6\%) males and $14.0 \%$ females had clustering of CVD risk factors. The body fluid composition was obtained by the BIA and anthropometric formula. TBW value was $43.3 \pm 5.1$ (L) for males, and $30.7 \pm 3.4$ (L) for females. The average values of TBW were lower than those of TBWwatson. In contrast, the values of the TBW/TBWwaston ration were $<1$ in both males and females, indicating a fluid volume deficit.

Age, BW, BMI, TBW, ICW, ECW, NECW, LBM, TBWwaston and DMI were statistically higher in clustering group than either in the single or in the none
Table 1 Baseline clinical characteristics of participants

\begin{tabular}{|c|c|c|c|}
\hline & Male & Female & $\mathbf{P}$ \\
\hline Number (n, \%) & $5467(69.2)$ & $2433(30.8)$ & / \\
\hline Age (years) & $38.8 \pm 8.5$ & $37.4 \pm 7.3$ & $<0.001$ \\
\hline Height (cm) & $172.7 \pm 6.0$ & $161.1 \pm 5.3$ & $<0.001$ \\
\hline BW (kg) & $76.9 \pm 11.6$ & $58.8 \pm 8.6$ & $<0.001$ \\
\hline BMI $\left(\mathrm{kg} / \mathrm{m}^{2}\right)$ & $25.8 \pm 3.5$ & $22.7 \pm 3.1$ & $<0.001$ \\
\hline \multicolumn{4}{|l|}{ Clinical findings } \\
\hline $\mathrm{SBP}(\mathrm{mmHg})$ & $131.7 \pm 15.7$ & $118.6 \pm 13.8$ & $<0.001$ \\
\hline $\mathrm{DBP}(\mathrm{mmHg})$ & $78.5 \pm 12.2$ & $70.9 \pm 10.0$ & $<0.001$ \\
\hline Hypertension (n,\%) & $1369(25.2)$ & $169(7.0)$ & $<0.001$ \\
\hline Diabetes (n, \%) & $336(6.2)$ & $31(1.3)$ & $<0.001$ \\
\hline Overweight (n, \%) & $3714(68.8)$ & 710 (29.6) & $<0.001$ \\
\hline Dyslipidemia (n, \%) & $2965(55.0)$ & $608(25.5)$ & $<0.001$ \\
\hline HBsAg (n, \%) & $168(3.5)$ & $42(2.0)$ & 0.001 \\
\hline Serum uric acid $(\mu \mathrm{mol} / \mathrm{L})$ & $353.1 \pm 82.7$ & $220.4 \pm 58.8$ & $<0.001$ \\
\hline Blood glucose (mmol/L) & $5.6 \pm 1.2$ & $5.2 \pm 0.8$ & $<0.001$ \\
\hline Hemoglobin (g/L) & $151.6 \pm 9.2$ & $126.5 \pm 12.0$ & $<0.001$ \\
\hline Hct $\%$ & $44.2 \pm 2.6$ & $37.5 \pm 3.1$ & $<0.001$ \\
\hline eGFR $\left(\mathrm{ml} / \mathrm{min} / 1.73 \mathrm{~m}^{2}\right)$ & $105.1 \pm 12.6$ & $104.1 \pm 14.1$ & 0.002 \\
\hline \multicolumn{4}{|l|}{ Body fluid composition } \\
\hline TBW (L) & $43.3 \pm 5.1$ & $30.7 \pm 3.4$ & $<0.001$ \\
\hline ICW (L) & $29.2 \pm 3.5$ & $20.6 \pm 2.3$ & $<0.001$ \\
\hline ECW (L) & $14.1 \pm 1.8$ & $10.1 \pm 1.1$ & $<0.001$ \\
\hline $\mathrm{NECW}(\mathrm{L} / \mathrm{m}))$ & $8.1 \pm 0.9$ & $6.3 \pm 0.6$ & $<0.001$ \\
\hline LBM (kg) & $59.1 \pm 7.0$ & $41.9 \pm 4.6$ & $<0.001$ \\
\hline ECW/TBW & $0.32 \pm 0.01$ & $0.33 \pm 0.01$ & $<0.001$ \\
\hline TBW waston (L) & $50.4 \pm 4.3$ & $34.9 \pm 3.1$ & $<0.001$ \\
\hline TBW/TBW watson & $0.86 \pm 0.05$ & $0.88 \pm 0.04$ & 0.001 \\
\hline $\mathrm{DMl}\left(\mathrm{kg} / \mathrm{m}^{2}\right)$ & $11.3 \pm 2.4$ & $10.8 \pm 2.3$ & $<0.001$ \\
\hline CVD risk factor $(n, \%)$ & & & $<0.001$ \\
\hline None & 969 (18.3) & $1269(54.1)$ & / \\
\hline Single & $1547(29.2)$ & $746(31.8)$ & / \\
\hline Cluster & $2791(52.6)$ & $329(14.0)$ & / \\
\hline
\end{tabular}

Arterial stiffness

cfPW $(\mathrm{cm} / \mathrm{s})$

$1379.2 \pm 171.1$

$1256.0 \pm 139.5$

$<0.001$

Abbreviations: BW, body weight; BMI, body mass index; SBP, systolic blood pressure; DBP, diastolic blood pressure; $\mathrm{Hb}$, hemoglobin; $\mathrm{Hct}$, hematocrit; eGFR, estimated glomerular filtration rate; CVD, cardiovascular disease; TBW, total body water; ICW, intracellular water; ECW, extracellular water; NECW, normalization extracellular water; LBM, lean body mass; DMI, dry mass index; cfPWV, carotid-femoral pulse wave velocity.

risk factor group $(\mathrm{P}<0.001)$. However, the ratio of $\mathrm{ECW} / \mathrm{TBW}$ and TBW/TBWwatson were lower in clustering group than other two groups $(\mathrm{P}<0.001)$. Hypovolaemia in clustering group (23.7\%) were statistically higher than either in the single or in the none risk factor group, which $17.0 \%$ and $10.0 \%$, respectively 
(P <0.001). cfPWV $(1419.0 \pm 172.5)$ were statistically higher in clustering group than either in the single or in the none risk factor group, which were 1308.4 \pm 139.2 and $1245.5 \pm 144.1 \mathrm{~cm} / \mathrm{s}$, respectively, $\mathrm{P}<0.001$, Table 2. As a categorical outcome, the percentage of the lowest quartiles of ECW/TBW and TBW/TBWwatson in clustering group were statistically higher than either in the single or in the none risk factor group, which was $44.9 \%$ vs. $36.9 \%$ and $25.1 \%, 36.2 \%$ vs. $32.2 \%$ and $25.0 \%$, respectively $(\mathrm{P}<0.001)$, Figure 1 .

After adjusted for potential confounders, age, hemoglobin, serum uric acid and hypovolaemia were associated with clustering of CVD risk factors, with ORs of 1.08 (95\% CI, 1.07-1.09), 1.04 (95\% CI, 1.04-1.05), 1.007 (95\% CI, 1.0061.007), 1.66 (95\% CI, 1.45-1.90), (Table 3).

Table 2 Body fluid composition according to CVD risk factors

\begin{tabular}{|c|c|c|c|c|}
\hline & None & Single & Cluster & $\mathbf{P}$ \\
\hline Prevalence (\%) & 29.3 & 30.0 & 40.8 & I \\
\hline Age (year) & $35.1 \pm 7.8$ & $38.3 \pm 8.1$ & $41.0 \pm 7.6$ & $\begin{array}{l}< \\
0.001\end{array}$ \\
\hline Male $(n, \%)$ & $969(43.3)$ & $1547(67.5)$ & 2791 (89.5) & $\begin{array}{l}< \\
0.001\end{array}$ \\
\hline BW (kg) & $59.3 \pm 8.1$ & $70.8 \pm 11.4$ & $80.5 \pm 11.1$ & $\begin{array}{l}< \\
0.001\end{array}$ \\
\hline $\mathrm{BMI}\left(\mathrm{kg} / \mathrm{m}^{2}\right)$ & $21.3 \pm 1.8$ & $24.7 \pm 3.0$ & $27.5 \pm 2.9$ & $\begin{array}{l}< \\
0.001\end{array}$ \\
\hline TBW (L) & $34.0 \pm 6.0$ & $39.1 \pm 6.8$ & $43.6 \pm 6.1$ & $\begin{array}{l}< \\
0.001\end{array}$ \\
\hline ICW (L) & $22.8 \pm 4.1$ & $26.3 \pm 4.6$ & $29.4 \pm 4.1$ & $\begin{array}{l}< \\
0.001\end{array}$ \\
\hline ECW (L) & $11.2 \pm 2.0$ & $12.7 \pm 2.2$ & $14.2 \pm 2.1$ & $\begin{array}{l}< \\
0.001\end{array}$ \\
\hline NECW (L/m)) & $6.7 \pm 0.9$ & $7.5 \pm 1.0$ & $8.2 \pm 0.9$ & $\begin{array}{l}< \\
0.001\end{array}$ \\
\hline LBM (kg) & $46.3 \pm 8.2$ & $53.3 \pm 9.3$ & $59.5 \pm 8.3$ & $\begin{array}{l}< \\
0.001\end{array}$ \\
\hline ECW/TBW & $0.33 \pm 0.01$ & $0.33 \pm 0.01$ & $0.32 \pm 0.01$ & $\begin{array}{l}< \\
0.001\end{array}$ \\
\hline $\begin{array}{l}\text { Hypovolaemia } \\
(n, \%)\end{array}$ & $223(10.0)$ & $397(17.0)$ & $738(23.7)$ & $\begin{array}{l}< \\
0.001\end{array}$ \\
\hline TBWwatson (L) & $39.0 \pm 6.8$ & $45.2 \pm 7.3$ & $50.7 \pm 5.8$ & $\begin{array}{l}< \\
0.001\end{array}$ \\
\hline $\begin{array}{l}\text { TBW/ } \\
\text { TBWwatson }\end{array}$ & $0.87 \pm 0.05$ & $0.86 \pm 0.05$ & $0.86 \pm 0.05$ & $\begin{array}{l}< \\
0.001\end{array}$ \\
\hline $\operatorname{DMl}\left(\mathrm{kg} / \mathrm{m}^{2}\right)$ & $9.1 \pm 1.4$ & $11.1 \pm 2.2$ & $12.6 \pm 2.1$ & $\begin{array}{l}< \\
0.001\end{array}$ \\
\hline cfPWV $(\mathrm{cm} / \mathrm{s})$ & $1245.5 \pm 144.1$ & $1308.4 \pm 139.2$ & $1419.0 \pm 172.5$ & $\begin{array}{l}< \\
0.001\end{array}$ \\
\hline
\end{tabular}

Abbreviations: CVD, cardiovascular disease; BW, body weight; BMI, body mass index; TBW, total body water; ICW, intracellular water; ECW, extracellular water; NECW, normalization extracellular water; LBM, lean body mass; DMI, dry mass index; cfPWV, carotid-femoral pulse wave velocity.

\section{Discussion}

Our study revealed a high prevalence of clustering of CVD risk factors in the adult population. Among the total participants, only $29.3 \%$ were free of any pre-defined CVD risk factors and $40.8 \%$ had clustering of CVD risk factors. The epidemiological studies have demonstrated that CVD risk factors could cluster in twins and among coronary prone family members $[25,26]$, suggesting that genetic factors might play an important role in the development of CVD risk factors. of these CVD risk factors, hypertension and diabetes mellitus are multifactorial disease under the influence of environmental factors [27].

Our study showed that age, blood uric acid, and hemoglobin were associated with the clustering of CVD risk factors. Many studies suggested that high levels of uric acid are independent risk factors of CVD $[28,29]$. In general population, increased level of hemoglobin is associated with atherosclerosis [30], while the mechanism is unknown. Studies have shown that hemoglobin was associated with the ratio of triglyceride/cholesterol [31], a risk factor for atherosclerosis. Furthermore, the elevated hemoglobin may increase blood viscosity and injury the vascular endothelium.

A multi-frequency bioelectrical impedance analysis (BIA) device is useful for assessing fluid and nutritional status in a noninvasive and easily accessible manner. We assessed fluid volume status in the population using the ECW/TBW and the TBW/TBWwatson ratio, which is calculated using the Watson formula adjusted for height, weight, age, and gender. Importantly, our study demonstrated that hypovolaemia was associated with clustering of major CVD risk factors. hypovolaemia might be a result of insufficient fluid intake. It has already been shown that there is a common hormone, angiotensin contributing to three of major diseases today, obesity, diabetes and hypertension [32]. Yet, this hormone is released under normal physiological conditions of hypovolaemia, which also stimulates the release of aldosterone. The presence of angiotensin and aldosterone is associated with metabolic dysfunction through increased insulin resistance, decreased glucose transport in skeletal muscle cells and vascular smooth muscle cells as well as decreased cardiac $\mathrm{Na}^{+} \mathrm{K}^{+}$ATPase activity [33]. Furthermore, increased water intakecould decreased the insulin resistance in animal models of obesity [34]. On another hand, it has been suggested that hypovolaemia increased the activity of the sympathetic nervous system [35]. Therefore, hypovolaemia induced reduction of cell volume causes insulin resistance, decreased glucose transport, and cellular metabolic dysfunction [36].

Our study has limitations that deserve mention. First, it was implemented on a voluntary bias and was 

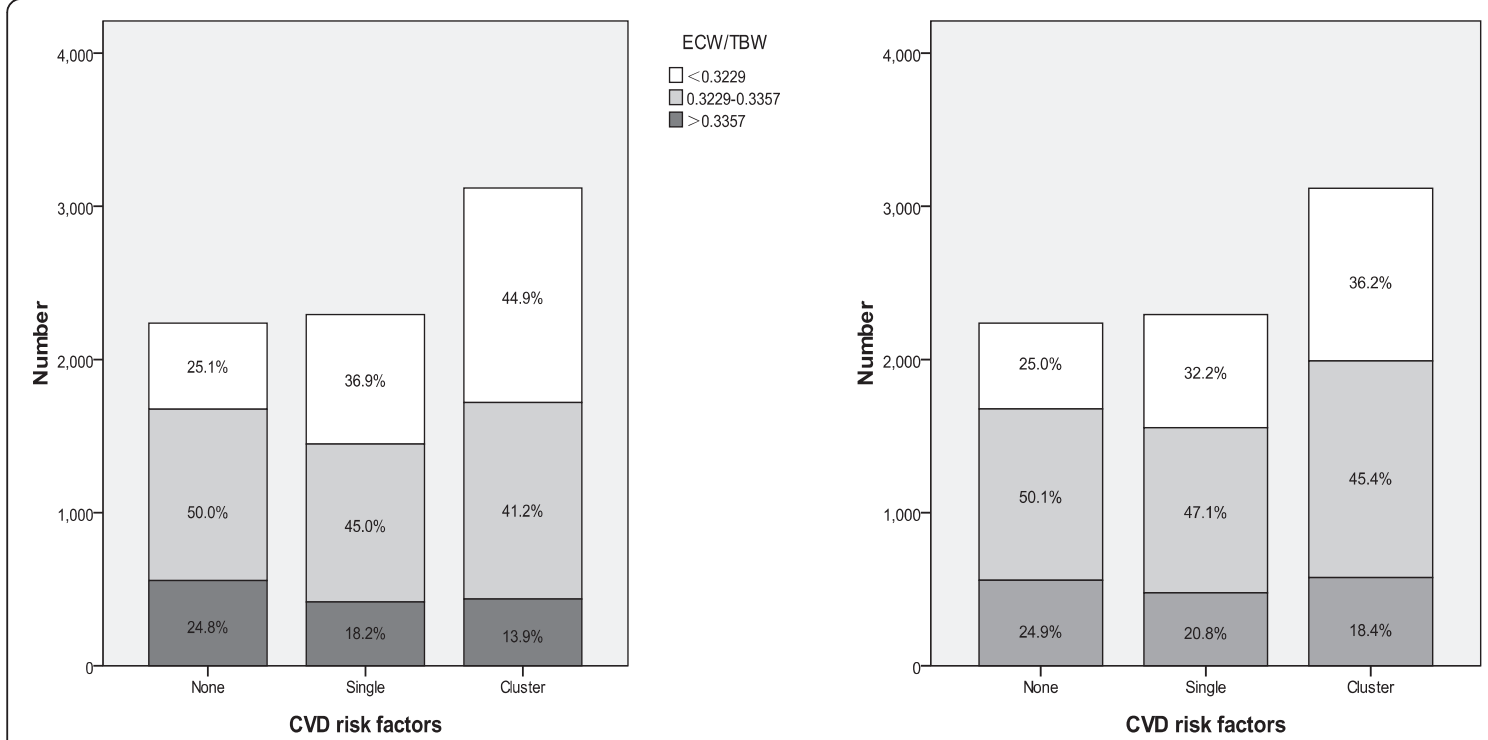

TBW/TBWwaston

Figure 1 The distribution of ECW/TBW and TBW/TBW watson in different CVD risk factor groups.

not based on a community-based screening. Selecting bias in the study limited the extension of the results from this study. The between-individual variation exists when using ECW/TBW to define volume status. Second, non-traditional risk factors of clustering of CVD risk factors were not investigated in the present study. This study excluded patients who were taking diuretics. These patients are likely to have hypertension or diabetes, therefore the prevalence of clustering $\mathrm{CV}$ risks may be underestimated. The association between fluid status and clustering of CVD risks in the diuretics taking group needs further investigations.

Table 3 Multivariate logistic regression analysis for association of clustering of CVD risk factors with different variables

\begin{tabular}{|c|c|c|c|c|}
\hline Variables & $\begin{array}{l}\text { Age- and Sex- } \\
\text { adjusted OR } \\
(95 \% \mathrm{Cl})\end{array}$ & $P$ & $\begin{array}{l}\text { Multivariable } \\
\text { adjusted OR } \\
(95 \% \mathrm{Cl})\end{array}$ & $\mathbf{P}$ \\
\hline Age & $\begin{array}{l}1.07 \\
(1.06-1.08)\end{array}$ & $<0.001$ & $\begin{array}{l}1.08 \\
(1.07-1.09)\end{array}$ & $<0.001$ \\
\hline Sex & $\begin{array}{l}0.15 \\
(0.13-0.17)\end{array}$ & $<0.001$ & $\begin{array}{l}0.92 \\
(0.75-1.12)\end{array}$ & 0.40 \\
\hline Hemoglobin & $\begin{array}{l}1.04 \\
(1.04-1.05)\end{array}$ & $<0.001$ & $\begin{array}{l}1.04 \\
(1.04-1.05)\end{array}$ & $<0.001$ \\
\hline $\begin{array}{l}\text { Serum uric } \\
\text { acid }\end{array}$ & $\begin{array}{l}1.007 \\
(1.006-1.008)\end{array}$ & $<0.001$ & $\begin{array}{l}1.007 \\
(1.006-1.007)\end{array}$ & $<0.001$ \\
\hline $\begin{array}{l}\text { Decreased } \\
\text { eGFR }\end{array}$ & $\begin{array}{l}1.63 \\
(0.31-8.62)\end{array}$ & 0.56 & $\begin{array}{l}1.64 \\
(0.29-9.2)\end{array}$ & 0.57 \\
\hline Hypovolaemia & $\begin{array}{l}1.84 \\
(1.62-2.1)\end{array}$ & $<0.001$ & $\begin{array}{l}1.66 \\
(1.45-1.90)\end{array}$ & $<0.001$ \\
\hline
\end{tabular}

Note: The regression model only included the none and the clustering groups. ${ }^{a}$ Except for OR of age and sex, all ORs were age and sex adjusted. ${ }^{\mathrm{b}}$ Model was adjusted for age, sex, hemoglobin, serum uric acid, decreased eGFR and hypovolaemia.
Third, our data was cross-sectional and do not provide an insight into the mechanisms responsible for the observed associations.

\section{Conclusions}

Our study indicates that clustering of CVD risk factors is common and positively associated with hypovolaemia in adult population. Future clinical trials need to be implemented to confirm whether increased consumption of fluids would be feasible for controlling the clustering of CVD risk factors.

\section{Competing interests}

The authors declare that they have no competing interests.

\section{Authors' contributions}

$\mathrm{KX}$ and $\mathrm{MX}$ participated in the study, analyzed the data, interpreted the results, and drafted the manuscript. YJ, ZS and CM participated in the survey and study design and collected the data. XD formed the study concept, interpreted the results, and revised the manuscript. All authors read and approved the final manuscript.

\section{Acknowledgements}

This work was funded by the Natural Science Foundation from Shandong Science and Technology Committee (ZR2010HL002). We would like to acknowledge Dr. Ju Liu for his generous sponsorship for revising the manuscript for important intellectual content.

\section{Author details}

'Department of Nephrology, Qianfoshan Hospital, Shandong University, No.16766, Jingshi Road, Jinan 250014, PR China. '2Department of Physical Examination Center, Qianfoshan Hospital, Shandong University, No.16766, Jingshi Road, Jinan, China. ${ }^{3}$ The Blood Purification Center, Shandong Veterans General Hospital, No. 23, Jiefang Road, Jinan, China. ${ }^{4}$ Department of Nephrology, Zhangqiu People's Hospital, No.1920, Zhangqiu MingShui huiquan road, Jinan, China. 


\section{References}

1. Chimonas T, Fanouraki I, Liberopoulos EN, Chimonas E, Elisaf M: Diverging trends in cardiovascular morbidity and mortality in a low risk population. Eur J Epidemiol 2009, 24(8):415-423.

2. Murray CJ, Lopez AD: Mortality by cause for eight regions of the world: Global Burden of Disease Study. Lancet 1997, 349(9061):1269-1276.

3. Yusuf S, Reddy S, Ounpuu S, Anand S: Global burden of cardiovascular diseases: part I: general considerations, the epidemiologic transition, risk factors, and impact of urbanization. Circulation 2001, 104(22):2746-2753.

4. Yusuf S, Hawken S, Ounpuu S, Dans T, Avezum A, Lanas F, McQueen M, Budaj A, Pais P, Varigos J, Lisheng L: Effect of potentially modifiable risk factors associated with myocardial infarction in 52 countries (the INTERHEART study): case-control study. Lancet 2004, 364(9438):937-952.

5. O'Donnell MJ, Xavier D, Liu L, Zhang H, Chin SL, Rao-Melacini P, Rangarajan S, Islam S, Pais P, McQueen MJ, Mondo C, Damasceno A, Lopez-Jaramillo P, Hankey GJ, Dans AL, Yusoff K, Truelsen T, Diener HC, Sacco RL, Ryglewicz D, Czlonkowska A, Weimar C, Wang X, Yusuf S: Risk factors for ischaemic and intracerebral haemorrhagic stroke in 22 countries (the INTERSTROKE study): a case-control study. Lancet 2010, 376(9735):112-123.

6. Boden-Albala B, Cammack S, Chong J, Wang C, Wright C, Rundek T, Elkind MS, Paik MC, Sacco RL: Diabetes, fasting glucose levels, and risk of ischemic stroke and vascular events: findings from the Northern Manhattan Study (NOMAS). Diabetes Care 2008, 31(6):1132-1137.

7. Gao B, Zhang L, Wang H, the China National Survey of Chronic Kidney Disease Working G: Clustering of major cardiovascular risk factors and the Association with unhealthy lifestyles in the Chinese adult population. PLoS One 2013, 8(6):e66780.

8. Ratner R, Goldberg R, Haffner S, Marcovina S, Orchard T, Fowler S, Temprosa M, Diabetes Prevention Program Research Group: Impact of intensive lifestyle and metformin therapy on cardiovascular disease risk factors in the diabetes prevention program. Diabetes Care 2005, 28(4):888-894.

9. Li G, Zhang P, Wang J, An Y, Gong Q, Gregg EW, Yang W, Zhang B, Shuai Y, Hong J, Engelgau MM, Li H, Roglic G, Hu Y, Bennett PH: Cardiovascular mortality, all-cause mortality, and diabetes incidence after lifestyle intervention for people with impaired glucose tolerance in the Da Qing Diabetes Prevention Study: a 23-year follow-up study. Lancet Diabetes Endocrinol 2014, 2(6):474-480.

10. Goodpaster BH, Delany JP, Otto AD, Kuller L, Vockley J, South-Paul JE, Thomas SB, Brown J, McTigue K, Hames KC, Lang W, Jakicic JM: Effects of diet and physical activity interventions on weight loss and cardiometabolic risk factors in severely obese adults: a randomized trial. JAMA 2010, 304(16):1795-1802

11. Kong $X$, Ma X, Cui M, Xu D: Association of clustering of major cardiovascular risk factors with chronic kidney disease in the adult population. Clin Nephrol 2014, 82(2):92-97.

12. Strippoli GF, Craig JC, Rochtchina E, Flood VM, Wang JJ, Mitchell P: Fluid and nutrient intake and risk of chronic kidney disease. Nephrology 2011, 16(3):326-334

13. Clark WF, Sontrop JM, Macnab JJ, Suri RS, Moist L, Salvadori M, Garg AX: Urine volume and change in estimated GFR in a community-based cohort study. Clin J Am Soc Nephrol 2011, 6(11):2634-2641.

14. Brooks DR, Ramirez-Rubio O, Amador JJ: CKD in Central America: a hot issue. Am J Kidney Dis 2012, 59(4):481-484.

15. Peraza S, Wesseling C, Aragon A, Leiva R, García-Trabanino RA, Torres C, Jakobsson $\mathrm{K}$, Elinder $\mathrm{CG}$, Hogstedt $\mathrm{C}$ : Decreased kidney function among agricultural workers in El Salvador. Am J Kidney Dis 2012, 59(4):531-540.

16. Bouby N, Bachmann S, Bichet D, Bankir L: Effect of water intake on the progression of chronic renal failure in the $5 / 6$ nephrectomized rat. Am $J$ Physiol 1990, 258(4 Pt 2):F973-F979.

17. Sugiura T, Yamauchi A, Kitamura H, Matsuoka Y, Horio M, Imai E, Hori M: High water intake ameliorates tubulointerstitial injury in rats with subtotal nephrectomy: possible role of TGF-beta. Kidney Int 1999, 55(5):1800-1810

18. Levey AS, Stevens LA, Schmid CH, Zhang YL, Castro AF 3rd, Feldman HI, Kusek JW, Eggers P, Van Lente F, Greene T, Coresh J, CKD-EPI (Chronic Kidney Disease Epidemiology Collaboration): A new equation to estimate glomerular filtration rate. Ann Intern Med 2009, 150(9):604-612.

19. Kong X, Ma Y, Chen J, Luo Q, Yu X, Li Y, Xu J, Huang S, Wang L, Huang W, Wang M, Xu G, Zhang L, Zuo L, Wang H, Chinese eGFR Investigation Collaboration: Evaluation of the chronic kidney disease epidemiology collaboration equation for estimating glomerular filtration rate in the Chinese population. Nephrol Dial Transplant 2013, 28(3):641-651.

20. Watson PE, Watson ID, Batt RD: Total body water volumes for adult males and females estimated from simple anthropometric measurements. Am J Clin Nutr 1980, 33(1):27-39.

21. Jaffrin MY: Body composition determination by bioimpedance: an update. Curr Opin Clin Nutr Metab Care 2009, 12(5):482-486.

22. Delles C, Zimmerli LU, McGrane DJ, Koh-Tan CH, Pathi VL, McKay AJ, Steedman T, Dargie HJ, Hamilton CA, Dominiczak AF: Vascular stiffness is related to superoxide generation in the vessel wall. $J$ Hypertens 2008, 26(5):946-955.

23. Myers GL, Cooper GR, Winn CL, Smith SJ: The Centers for Disease ControlNational Heart, Lung and Blood Institute Lipid Standardization Program. An approach to accurate and precise lipid measurements. Clin Lab Med 1989, 9(1):105-135.

24. Zhou BF: Cooperative Meta-Analysis Group of the Working Group on Obesity in C: predictive values of body mass index and waist circumference for risk factors of certain related diseases in Chinese adults-study on optimal cut-off points of body mass index and waist circumference in Chinese adults. Biomed Environ Sci 2002, 15(1):83-96.

25. Carmelli D, Cardon LR, Fabsitz R: Clustering of hypertension, diabetes, and obesity in adult male twins: same genes or same environments? Am J Hum Genet 1994, 55(3):566-573.

26. Mitchell BD, Kammerer CM, Blangero J, Mahaney MC, Rainwater DL, Dyke B, Hixson JE, Henkel RD, Sharp RM, Comuzzie AG, VandeBerg JL, Stern MP, MacCluer JW: Genetic and environmental contributions to cardiovascular risk factors in Mexican Americans. The San Antonio Family Heart Study. Circulation 1996, 94(9):2159-2170.

27. Satko SG, Sedor JR, lyengar SK, Freedman BI: Familial clustering of chronic kidney disease. Semin Dial 2007, 20(3):229-236.

28. Viazzi F, Garneri D, Leoncini G, Gonnella A, Muiesan ML, Ambrosioni E, Costa FV, Leonetti G, Pessina AC, Trimarco B, Volpe M, Agabiti Rosei E, Deferrari G, Pontremoli R: Serum uric acid and its relationship with metabolic syndrome and cardiovascular risk profile in patients with hypertension: insights from the I-DEMAND study. Nutr Metab Cardiovasc Dis 2014, 24(8):921-927.

29. Skak-Nielsen H, Torp-Pedersen C, Finer N, Caterson ID, Van Gaal L, James WP, Maggioni AP, Sharma AM, Coutinho W, Andersson C: Uric acid as a risk factor for cardiovascular disease and mortality in overweight/obese individuals. PLoS One 2013, 8(3):e59121.

30. Kawamoto R, Tabara Y, Kohara K, Miki T, Kusunoki T, Katoh T, Ohtsuka N, Takayama S, Abe M: A slightly low hemoglobin level is beneficially associated with arterial stiffness in Japanese community-dwelling women. Clin Exp Hypertens 2012, 34(2):92-98.

31. Shimizu Y, Nakazato M, Sekita T, Koyamatsu J, Kadota K, Yamasaki H, Goto H, Takamura N, Aoyagi K, Maeda T: Association between hemoglobin and diabetes in relation to the triglycerides-to-high-density lipoprotein cholesterol (TG-HDL) ratio in Japanese individuals: the Nagasaki Islands Study. Intern Med 2014, 53(8):837-843.

32. Thornton SN: Angiotensin, the hypovolaemia hormone, aggravates hypertension, obesity, diabetes and cancer. J Intern Med 2009, 265(5):616-617.

33. Thornton SN: Angiotensin-induced metabolic dysfunction. $J$ Hypertens 2009, 27(3):658-659.

34. Thornton SN, Even PC, van Dijk G: Hydration increases cell metabolism. Int J Obes 2009, 33(3):385-386

35. Yun AJ, Lee PY, Bazar KA: Clinical benefits of hydration and volume expansion in a wide range of illnesses may be attributable to reduction of sympatho-vagal ratio. Med Hypotheses 2005, 64(3):646-650.

36. Schliess F, Reinehr R, Haussinger D: Osmosensing and signaling in the regulation of mammalian cell function. FEBS J 2007, 274(22):5799-5803.

\section{doi:10.1186/1471-2261-14-151}

Cite this article as: Kong et al: Hypovolaemia was associated with clustering of major cardiovascular risk factors in general population. BMC Cardiovascular Disorders 2014 14:151. 